\title{
Control, regulation and command system of hydronic radiant floors heating by wireless and energy harvesting sensors and actuators
}

\author{
Gilberto Batista ${ }^{1,}$, Pedro Dinis Gaspar ${ }^{2, b}$ and Pedro D. Silva ${ }^{3, c}$ \\ 1, 2, 3University of Beira Interior, Dept. of Electromechanical Engineering, 6201-001 Covilhã, \\ Portugal \\ a3gbatista@gmail.com, bdinis@ubi.pt, 'dinho@ubi.pt
}

Keywords: Wireless, Energy harvesting, Sensors, Actuators, Hydronic radiant floors heating.

\begin{abstract}
This paper presents the development of an innovative control, regulation and command system for hydronic radiant floors, more flexible and efficient that guarantees a better thermal comfort to the user and simultaneously improves the energy efficiency of this type of heating system. The majority of the actual control of hydronic radiant floors is done by thermostats that measure the air temperature and control the actuators (pumps and valves) in order to maintain the room at the specified temperature. These systems requires the frequent adjustment of thermostats set-point in order to obtain thermal comfort as it depends on other factors than just the air temperature, such as, the air humidity, external environmental conditions, radiant temperature, among others. This paper presents a control, regulation and command solution that requires minimum user intervention, as the user only has to choose the desirable thermal comfort level. The control algorithm is based on the calculation of PMV (Predicted Mean Vote) index as defined on Thermal Comfort Standard ISO 7730. Another advantage of the proposed system is related to the wireless and energy harvesting sensors and actuators that provide much more flexibility to the system.
\end{abstract}

\section{Introduction}

A hydronic radiant floor heating (RFH) system heats the floor by circulating water through tubing that is laid inside or underneath the floor in a continuous series of loops. The water is heated after passing through a heat source like a boiler or a heat pump. The water at low temperature $\left(30^{\circ} \mathrm{C}\right.$ to $45^{\circ} \mathrm{C}$ ) transfers heat to the floor that latter transfers it to the environment. The flow rate is regulated by a single pump and a general solenoid valve for each room in order to individually control the heat released. A RFH system increases the efficiency of heat generators since it uses low temperature water for operation and simultaneously allowing a better temperature profile in the heated room providing to the occupant a higher thermal comfort as stated by Fanger et al. [1]. The energy efficiency of this system can be improved using control, regulation and command solutions that ensure maximum thermal comfort. Buckley [2] and Strand \& Pedersen [3] studied the experimental behaviour and developed numerical and analytical models in order to analyse and improve the efficiency of RFH systems. This efficiency can still be improved by alternative control, regulation and command strategies that provide greater flexibility and adaptability. There are several possible methods for controlling a RFH system. The most common is to use on-off control valves with air temperature feedback. Other type of control systems were studied by Cho \& Zaheeruddin [4] and Ahn \& Song [5]. Our control system proposal is based on the measurement of air and water temperatures and air relative humidity, allowing a better interpretation of the environment by the controller. The regulation and command strategy relies on the use of on-off solenoid valves and a single-speed pump. The control algorithm is based on the calculation of the PMV index defined in ISO 7730 [6] which allows the controller to command the actuators in order to achieve a comfort class A category, as set by this standard. 


\section{Wireless and energy harvesting sensors and actuators}

ASHRAE [7] review the various methods for signal transmission used in HVAC systems. Depending on the communication protocol used the signal transmission can be made by wired or wireless. Typically, in most of HVAC systems, it is made by wire, but it is known that installation costs are around 20 to $80 \%$ of the total cost of sensors and control points. Therefore, reducing or eliminating these installation costs has a significant effect on the overall system cost. Wireless sensors and actuators have been developed and improving the ability to acquire information from the physical world. Wireless technologies offer significant opportunities in sensors and controllers for use at home especially in reducing the cost of data acquisition systems and control devices. Low cost wireless sensors in control systems also allow the use of more sensors providing more feedback data to the controller in order to control the process more effectively and provide greater comfort to the occupants. The sensors and control devices are usually connected to the network through radio frequency (RF) and sometimes by optical signals (infrared). The devices can communicate in just one direction (transmit only) or bidirectionally (transmitting and receiving). Most RF products transmit in industrial, scientific or medical frequency bands already defined by the FCC (Federal Communications Commission), which requires no license. Currently, with the technology development, some wireless devices have energy harvesting. They capture energy locally for their own operation: solar cells collecting energy from the ambient light, electrodynamic converters absorbing energy from a switching operation (button pressure) or even thermoconverters making use of Peltier effect. For this end, our control system proposal makes use of EnOcean modules [8-9] which combine micro-energy converters with ultra-low power electronics and reliable wireless communications. The operating principle of these modules is shown in Fig. 1.

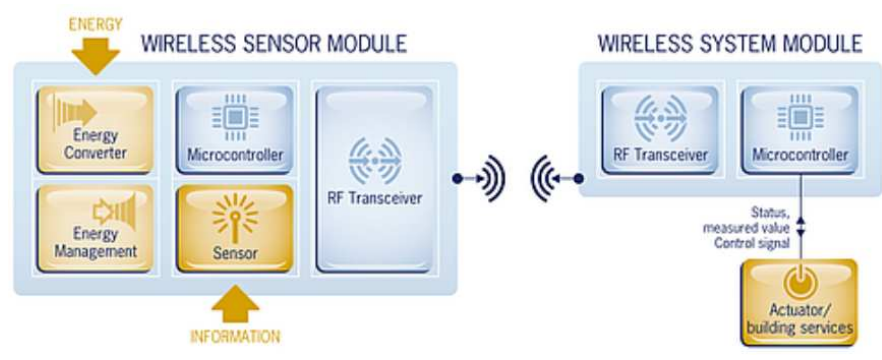

Fig. 1 - Energy Harvesting Wireless Sensor Solution from EnOcean [8].

The wireless sensor module receives power by one energy harvesting process. It captures the sensor information; an analog-to-digital conversion is performed by the microcontroller, which in turn sends telegrams using the RF transceiver of the sensor module to the main controller. The latter will read the telegram and control the actuators accordingly to the decision algorithm. The wireless sensor modules used are: the PTM200 with electrodynamic energy harvesting (Push button multichannel switch); the STM300 (programmable and bidirectional transmitter/receiver at $868 \mathrm{MHz}$ ); the STM31x (plug\&play wireless transmitter); and the STM330 (small dimensions wireless transmitter), that captures energy from either local illuminance, thermal or motion energy. The TCM300 and TCM320 wireless system modules manage the sensors information and control the actuators. These wireless transceiver modules have no energy harvesting and they are programmed using the Dolphin API library. The sensor and controller modules are shown in Fig. 2.

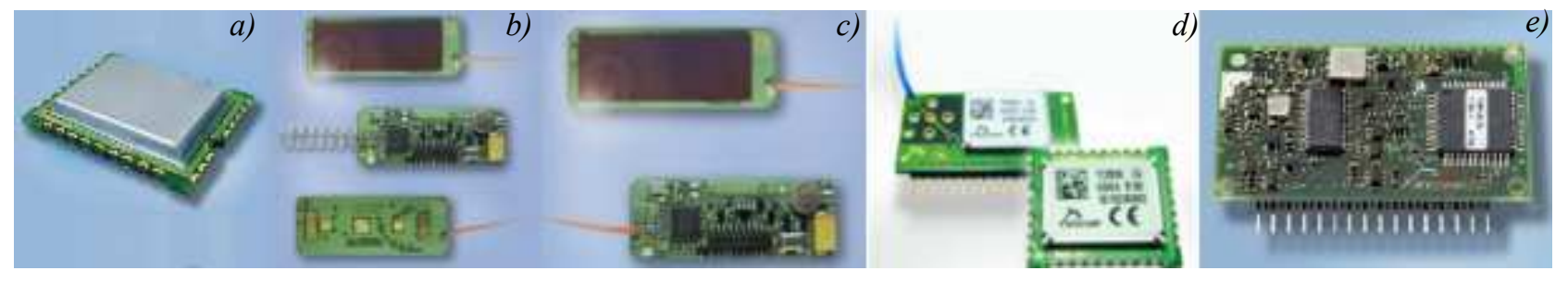

Fig. 2 - a) STM300; b) STM31x; c) STM330; d) TCM300 е TCM320; e)TCM110 [9]. 


\section{Proposal for control system configuration}

The control system is designed to regulate the temperature of the radiant floor in order to provide thermal comfort to the occupants. Thus, the device calculates regularly the PMV index in each room, using data from the temperature and humidity sensors installed in each room. Based on this index, the system will control the valves aperture and the pump operation, consequently providing more or less heat to the floor to achieve a thermal comfort near the range of class A category $(-0.2<$ PMV $<0.2)$. A diagram of the general operation of this system is shown in Fig. 3.

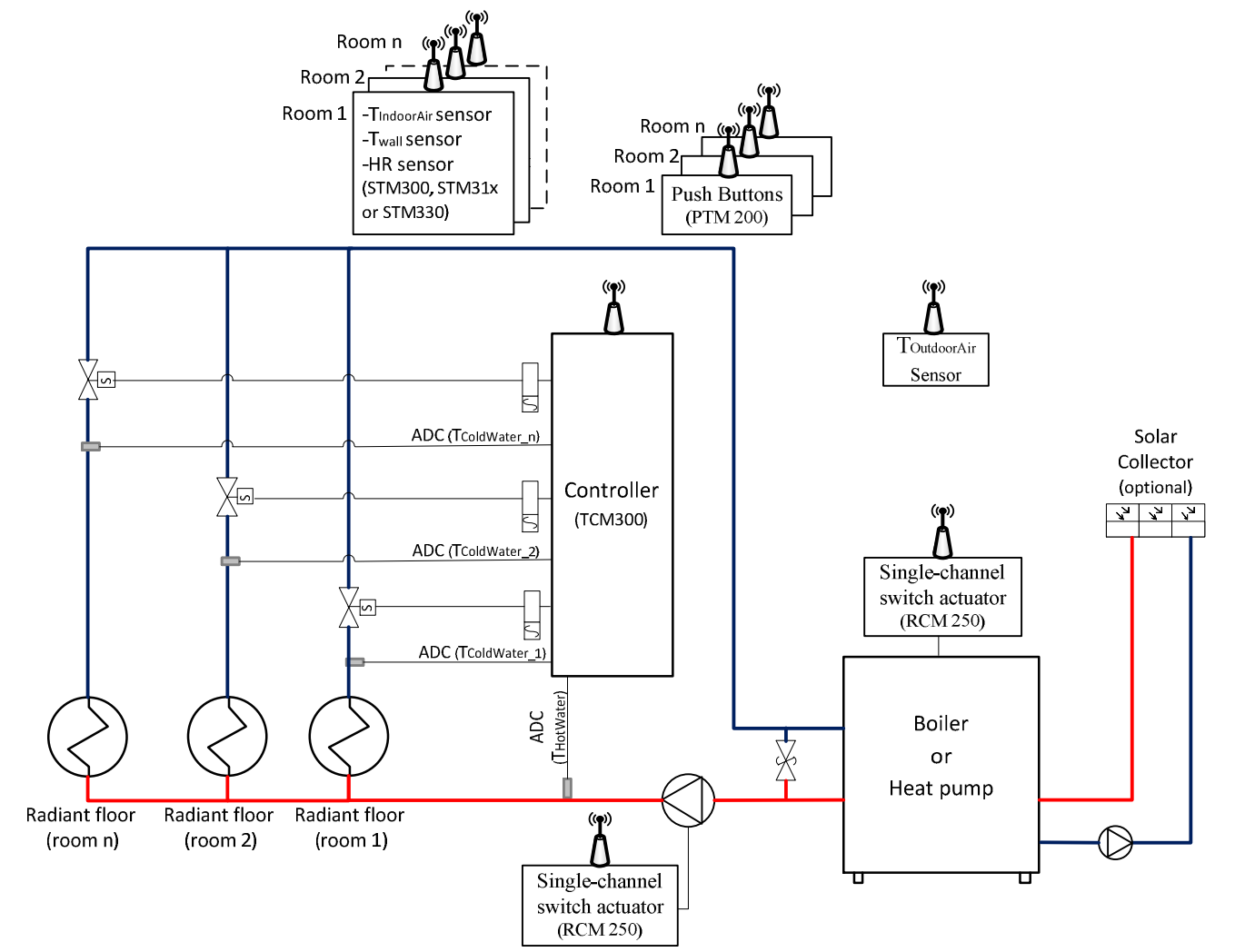

Fig. 3 - Control, regulation and command system using wireless and energy harvesting components.

Our control system proposal uses the calculation method for the surface temperature of a RFH heating/cooling system proposed by Jin et al. [10]. The calculation method results are in agreement with the experimental and numerical values available in the literature for this system. Afterwards, the PMV index calculation procedure within the control system follows the equations provided by Fanger et al. [1]. Thus, the controller calculates regularly the PMV index value for each room to command correctly the solenoid valve that allows the passage of hot water to the respective room floor circuit. The description of the overall operation of this wireless controller is depicted in the flowchart shown in Fig. 4.

\section{Conclusions}

This paper presents the development of an innovative control, regulation and command system for hydronic radiant floor heating (RFH). It illustrates an alternative strategy to control RHF systems more flexible and efficient which ensures a better thermal comfort with little intervention by the user. It assumes no temperature set point as the controller estimates the PMV index based on the building characteristics, the most common clothes and occupants activity. The PMV index is used as feedback to control the floor temperature in order to achieve thermal comfort. This control system solution uses wireless and energy harvesting sensors and actuators, enabling an easier and faster installation without wires and maintenance free. The proposed algorithm is enough versatile to be adapted to other heating systems. 


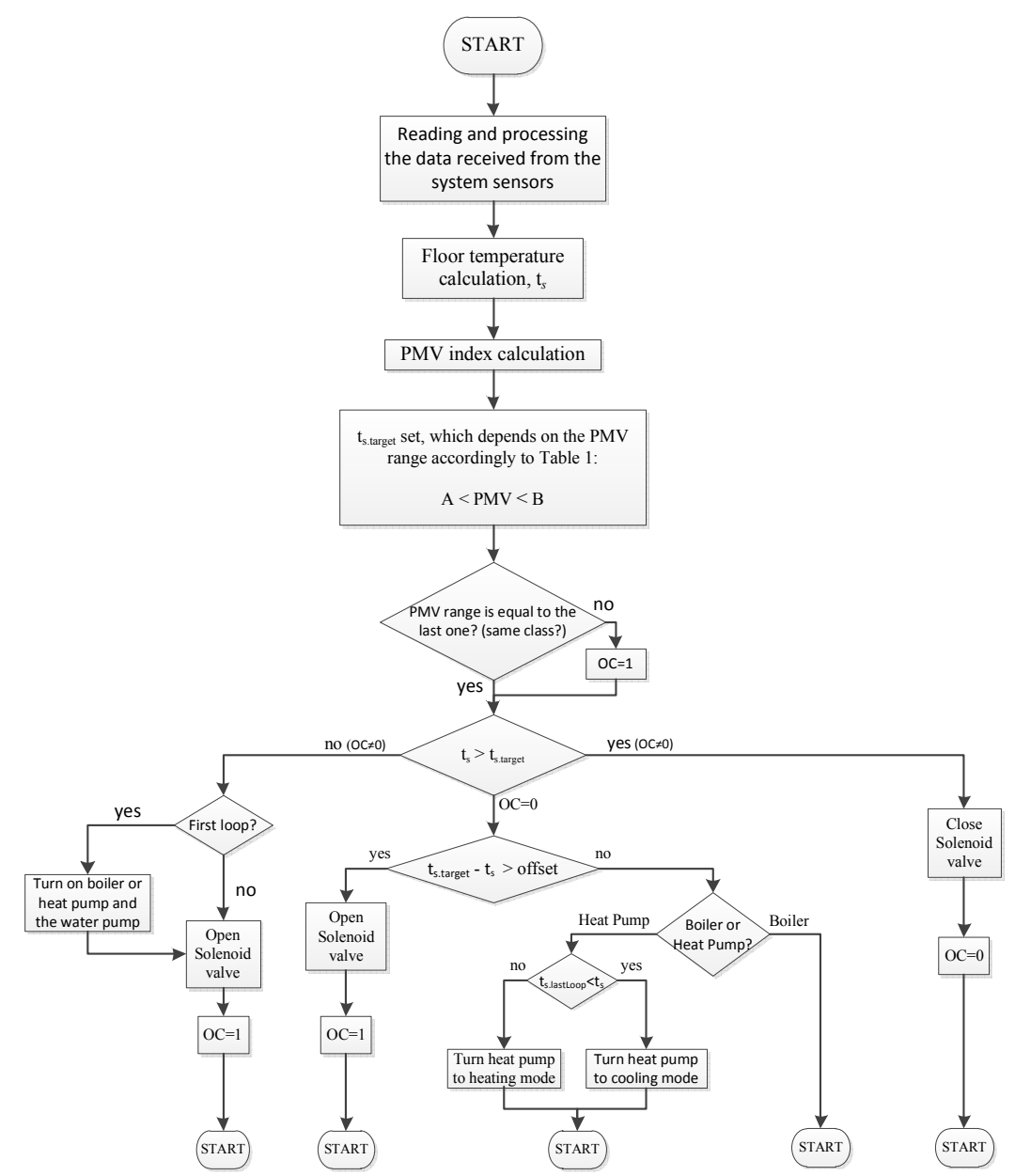

Fig. 4 - Flowchart of the controller program based on the PMV index.

\section{References}

[1] L. Fanger, G. Clausen and P.O. Fanger: Impact of temperature and humidity on the perception of indoor air quality. Indoor Air 8(2) (1998), p. 80-90.

[2] N.A. Buckley: Application of radiant heating saves energy. ASHRAE Journal 31(9) (1989), p. $17-26$.

[3] R.K. Strand and C.O. Pedersen: Analytical verfication of heat source transfer functions. First Joint Conference of International Simulation Societies, Zurich, Switzerland (1994).

[4] S.H. Cho and M. Zaheer-uddin: Predictive control of intermittently operated radiant floor heating systems. Energy Conversion and Management 44(8) 2003, p. 1333-1342.

[5] B.C. Ahn and J.Y. Song: Control characteristics and heating performance analysis of automatic thermostatic valves for radiant slab heating system in residential apartments. Energy 35(4) (2010), p. 1615-1624.

[6] ISO: ISO 7730, Ergonomics of the thermal environment - Analytical determination and interpretation of thermal comfort using calculation of the PMV and PPD indices and local thermal comfort criteria. International Organization for Standardization - ISO (2005).

[7] ASHRAE: 2009 ASHRAE Handbook - Fundamentals (SI Edition). American Society of Heating, Refrigerating and Air-Conditioning Engineers, Inc.- ASHRAE (2009).

[8] EnOcean: Energy harvesting wireless technology, Available: http://www.enocean.com/en/energy-harvesting-wireless/ (accessed 2012, April, 11).

[9] EnOcean: EnOcean Modules \& Accessories, Available: http://www.enocean.com/en/enocean_modules/ (accessed 2012, April, 16).

[10] X. Jin, X. Zhang and Y. Luo: A calculation method for the floor surface temperature in radiant floor system. Energy and Buildings 42(10) (2010), p. 1753-1758. 